\title{
Survival of a patient after self-injection of paraquat and surgical excision of the injection site
}

\author{
R Fernando \\ Ceylon Medical Journal 2015; 60: 66
}

\section{Introduction}

Paraquat, a highly toxic bipyridyl compound, is widely used as a herbicide that causes serious morbidity and mortality when ingested. Death usually occurs within two days of ingestion of $50 \mathrm{mg} / \mathrm{kg}$ [1]. At lower doses death from pulmonary fibrosis is delayed for a few weeks as the toxic compound accumulates in lung tissue where free radicals are formed, lipid peroxidation is induced and nicotinamide adenine dinucleotide phosphate (NADPH) is depleted.The first case of fatal paraquat poisoning by subcutaneous injection was reported in 1967 [2]. Since then, a few more cases of parenteral paraquat poisoning have been reported. All were fatal. We report a patient with subcutaneous paraquat poisoning who survived following removal of the skin and subcutaneous tissue.

\section{Case report}

Patient was a 19-year-old school girl who was scolded by her parents about an affair she had with a classmate. Soon after, she injected her left forearm with about $1 \mathrm{ml}$ of $20 \%$ paraquat subcutaneously. She was admitted under our care 10 hours after the incident. She was complaining of faintishness. The injection site was red and swollen. She had immediate surgery to remove the skin and underlying subcutaneous and muscle tissue with a $7 \mathrm{~cm}$ long incision. The histology of the tissue showed necrosis. Urine was positive for paraquat with the dithionite test. The syringe and the needle showed residual paraquat with the same test. Liver and renal function tests showed no abnormality and she had an uneventful recovery. She left hospital seven days later and was in good health after six months. Recovery of this patient was due to immediate surgical removal of the paraquat containing tissue and this procedure is recommended for subcutaneous and intramuscular paraquat injections.

\section{Discussion}

The minimum lethal dose of paraquat by oral ingestion in humans is about $20-35 \mathrm{mg} / \mathrm{kg}$ body weight. Toxic dose for injected paraquat is not known. Parenteral paraquat poisoning is extremely rare and it is associated with attempted suicide, except for one case of homicidal poisoning where a health worker was injected with paraquat [3]. Four cases of intravenous paraquat poisoning have been documented. An intravenous drug abuser injected paraquat in an effort to commit suicide and he died in 2 days [4]. In the other reported cases one died within 3 days and the other two patients died within five days $[5,6]$. All died from multiple organ failure.

In the past a 16-year-old girl who was admitted after subcutaneous injection of paraquat had died 17 days later from pulmonary fibrosis despite immediate surgical excision and subsequent antioxidant treatment with $\mathrm{N}$-acetylcysteine [7]. The present case appears to be the first in the literature where excision of skin and subcutaneous tissue saved the life of a patient after paraquat injection. Therefore, this procedure can be recommended for all cases of subcutaneous paraquat injections.

\section{Acknowledgements}

The author wishes to thank Dr. M. Gunasekera, the Consultant Surgeon who performed the surgery in this patient.

\section{Conflicts of interest}

We declare that there are no conflicts of interest.

\section{References}

1. Bismuth C, Garnier R, Baud FJ, Muszynski J, Keyes C. Paraquat poisoning. An overview of the current status. Drug Saf 1990; 5: 243-51.

2. Almog C, Tal E. Death from paraquat after subcutaneous injection. Br Med J 1967; 3: 721.

3. Chandrasiri N. The first ever report of homicidal poisoning by intramuscular injection of gramoxone (paraquat). Ceylon Med J 1999; 44: 36-9.

4. Chen HW, Tseng TK, Ding LW. Intravenous paraquat poisoning. J Chin Med Assoc 2009; 72: 547-50.

5. Choi Y, Cho K, Yoon S, Lee H, Choi Y. A case of paraquat intoxication caused by intravenous injection. Am J Emerg Med 2008; 26: 836.

6. Hsu HH, Chang CT, Lin JL. Intravenous paraquat poisoning-induced multiple organ failure and fatality - a report of two cases. J Toxicol Clin Toxicol 2003; 41: 87-90.

7. Fernandez P, Bermejo AM, Lopez-Rivadulla M, Cruz A, Rodriguez E, Otero A. A fatal case of parenteral paraquat poisoning. Forensic Sci Int 1991; 49: 215-24.

Faculty of Medicine, University of Colombo, Sri Lanka.

Correspondence: RF, e-mail: <ravindrafernando@hotmail.co.uk>. Received 3 November 2014 and revised version accepted 10 January 2014. 